\title{
The Effect of NEES on the Occurrence of Caspase-3 in the Cerebellum of Rats with Transient Global Ischemia
}

\begin{abstract}
The cerebellum is known to control balance, equilibrium, and muscle tone. If the cerebellum becomes damaged, the body is unable to retain its balancing functions or involuntary muscle movement. This is why, in stroke patients, there is a high risk of functional disability, as well as a myriad of other disabilities secondary to stroke.

Ischemia was induced in SD mice by occluding the common carotid artery for 5 minutes, after which blood was reperfused. Needle electrode electrical stimulation(NEES) was applied to acupuncture points, at 12, 24, and 48 hours post-ischemia on the joksamri. Protein expression was investigated through caspase- 3 antibody immuno-reactive cells in the cerebral nerve cells and Western blotting.

The results were as follows: The number of caspase- 3 reactive cells in the corpus cerebellum 12 and 24 hours post-ischemia was significantly ( $p<.05$ ) smaller in the NEES group compared to the Gl group. caspase-3 expression 12 and 24 hours post-ischemia was significantly(p<.05) smaller in the NEES group compared to the Gl group.

Based on these results, NEES seems to have a significant effect on Caspase -3 in the cerebellum in an ischemic state at 12 and 24 hours post ischemia, NEES delays the occurrence of early stage apoptosis-inducing Caspase -3 , delaying and inhibiting apoptosis. Further systematic studies will have to be conducted in relation to the application of this study' $s$ results on stroke patients.
\end{abstract}

Key words: Ischemia; Stroke; Apoptosis; Needle Electrode Electrical Stimulation; Joksamri; Caspase-3
Jung Sook Lee ${ }^{a}$, Young Wha Song ${ }^{b}$, Sung Won Kim

${ }^{a}$ Dongju University College, Busan; ${ }^{b}$ Dongnam Health College, Suwon

Received : 02 April 2014

Revised : 20 June 2014

Accepted : 03 September 2014

Address for correspondence

Sung Won Kim, PT, Ph.D

Department of Physical Therapy, Dongnam Health University, 50, Cheoncheon-ro 74-gil, Jangan-gu. Suwon-si, Gyeonggi-do, korea Tel : 82-31-249-6447

Email : johnswkim@dongnam.ac.kr

\section{INTRODUCTION}

Ischemia, the leading cause of cerebral infarct, is related to synaptic plasticity and apoptosis caused by damage from an ischemic state or trauma(1). The two known mechanisms behind cell death are apoptosis and necrosis.

The cerebellum is known to control balance, equilibrium, and muscle tone. If the cerebellum becomes damaged, the body is unable to retain its balancing functions or involuntary muscle movement. This is why, in stroke patients, there is a high risk of functional disability, as well as a myriad of other disabilities secondary to stroke.

Apoptosis is known to occur repeatedly and over long periods of time, even with seemingly mild degrees of shock and without direct damage to brain tissue(2). Necrosis occurs in areas that have received direct trauma, as well as from secondary factors such as elevated intracranial pressure, hypoxia, and ischemia(3). There is also the penumbra, an area outside the actual place of necrosis or damage, in which hypoxia, ischemia and lack of blood flow cause a decrease in action potential, but ATP metabolism and ionic homeostasis through the cell membrane are maintained(4). Apoptosis is the main mechanism behind cell death in the penumbra, and, with proper treatment following a hypoxic event leading to ischemic brain damage, the penumbra does have potential for rehabilitation(5). Not only does ischemic brain damage cause intrinsic cellular damage to the cerebellar parenchyma, it also causes extrinsic 
inflammatory reactions, including accumulation of macrophages, which show a peak in the penumbra at 2-3 days following the initial damage(6).

When ischemia occurs, a protein related to the apoptosis-inducing protein Bax called cytochrome C is isolated from the mitochondria. The isolated cytochrome $\mathrm{C}$ activates Caspase-9(7), a central factor in the mechanism behind the cell death process(8), which causes cell death by directly dividing other caspases. Caspase-3 in particular is known to be a main effector caspase which destroys a variety of parenchyma.

This study investigated the changes in Caspase-3 in relation to cell death in the cerebellum in global ischemia-induced rats at 12,24 , and 48 hours postischemia, as well as the effects of NEES treatment following ischemic stroke.

\section{METHODS}

\section{Subjects}

Subjects were 8 week-old, specific pathogen free, male SD rats which had been allowed to adjust to the laboratory environment for over 1 week and weighed approximately 300g(Orient BIO, Co., Gapyung, South Korea). Appropriate amounts of food and water were given, and the laboratory was kept at $22 \pm 1 \mathrm{C}$ and 45-55\% humidity.

\section{Ischemia induction model and NEES}

Subjects were anesthetized using 3\% isoflurane(Choongwae Pharma Corportation, Korea). Incisions $2 \mathrm{~cm}$ in length were made in the center of both common carotid arteries, the vagus nerves were separated, and circulation in both arteries was completely cut off using non-absorbent thread. Five minutes later, the thread was removed to allow the reperfusion of blood.

The subjects were divided into the control group (no closing of the common carotid artery), the global ischemia(GI) group(common carotid artery closed), and the Needle electrode electrical stimulation(NEES) group(NEES treatment applied after GI induction). Subjects in the GI group were allowed to recover for 30 minutes at 12, 24, and 48 hours after induction of GI with $3 \%$ isoflurane as an anesthetic. Subjects in the NEES group were given NEES treatment by using a needle electrode electrical stimulator(PG6, ITO, Japan, 9V) at the right and left Joksamri (ST36) for 30 minutes in concurrence with anesthesia with $3 \%$ isoflurane at 12,24 , and 48 hours after induction of GI. NEES was done using a $2 \mathrm{~Hz}$ current, and strength was adjusted according to muscle movement around the stimulation point.

\section{Immunohistology}

Immunohistological studies were performed on cerebellum tissue samples of GI-induced rats. Fixed brain tissue was freeze sectioned using 4\% paraformaldehyde, and the free-floating method and a Vectastain ACB Kit(Vector, USA) was used. The microtomed tissue was washed 3 times for 5 minutes each with $0.1 \mathrm{M}$ PBS, and blocking was performed using 1\% H2O2(peroxidaseblocking,0.1MPBS). The samples were then leftin $2 \%$ normal goat serum for 30 minutes at room temperature. Anti-PARP was used as the primary anti-body. After leaving the primary anti-body to react for 3 days at $4^{\circ} \mathrm{C}$, it was washed 3 times for 5 minutes each with 0.1M PBS, after which it was left to react with the secondary anti-body for 1 day at $4^{\circ} \mathrm{C}$. After DAB color development(Sigma,USA), tissue samples were put onto slides using $1 \%$ gelatin, dried in a dry oven for approximately 2 hours, dehydrated and madeclear, thenmounted using permount solution(Fisher, USA).

\section{Western blotting}

The removed cerebellum was divided according to area and evenly broken down using a homogenizer. It was centrifuged at $1000 \mathrm{rpm}$ and the supernatent was discarded, after which it was washed twice with cold PBS. After centrifuging, a Protein assay kit (Bio-rad) was used to measure the optical density of the protein at $750 \mathrm{~nm}$. The quantified protein was mixed with a lysis buffer and sample buffer $60 \mathrm{mM}$ tris; pH 6.8, $10 \%$ glycerol, $2 \%$ SDS, $0.01 \%$ bromophenol blue) in order to even the amount of protein, then boiled at $100^{\circ} \mathrm{C}$ for 5 minutes on a heat block. This was centrifuged and the specimein collected. A separating gel(12-15\%) was made by pouring into a clean electrophoresis glass plate a combination of $30 \%$ polyacrylamide mix, thrice distilled water, $1.5 \mathrm{M}$ tris(pH 8.8), $10 \%$ SDS, $10 \%$ ammonium persulfate (produced that day), and TEMED. $10 \mathrm{x}$ stock of electrophoresis running buffer was made by melting $30.0 \mathrm{~g}$ tris base, $144 \mathrm{~g}$ glycine, and $10 \mathrm{~g}$ SDS into $1 \mathrm{~L}$. $10-20 \mu \mathrm{L}$ of the quantified protein was added, and $100 \mathrm{~V}$ was run for approximately 1 hour. The transfer buffer was made by adding $3.03 \mathrm{~g}$ tris-base, $14.63 \mathrm{~g}$ glycine, and $200 \mathrm{~mL}$ methane to $1 \mathrm{~L}$. It was stored at 4 ${ }^{\circ} \mathrm{C}$ before use. The thin membrane was washed with a 
TTBS solution ( $\mathrm{pH} 7.5$ ) composed of $200 \mathrm{mM}$ trisbase, $1.54 \mathrm{M} \mathrm{NaCl}$, thrice-distilled water, and 20 tween. It was them put into $5 \%$ lac defloratum and left for a day at $4^{\circ} \mathrm{C}$.

The next day, after removing the blocking solution, a primary antibody identical to the one used in immune staining was reacted for 1 hour with the thin membrane put into a solution made by diluting $5 \%$ lac defloratum to 1000 times its original concentration. This was then washed 3 times with TTBS solution for 10 minutes each. A secondary antibody was reacted for 1 hour with the thin membrane put into a solution made by diluting 5\% lac defloratum to 1000 times its original concentration. After removing the solution, this was then washed 3 times with TTBS solution for 10 minutes each. Solutions A and B from the ECL kit were well combined at a ratio of 40:1 and this was used to wet the thin membrane. After 1 hour, the thin membrane was put on a cassette and photo-sensitized using x ray film. After photo-sensitizing for a period of time, expression bands were checked and a fixator was used for fixing. After fixing, the bands were washed in clean running water, dried, scanned, and a concentration meter(Bio-rad) was used to measure the optical density of each band.

\section{Data analysis}

All data collected in this study were encoded and analyzed using a computerized statistical analysis program(SPSS 12.0K/PC). In order to find out the effects of the control group, global ischemia group, and NEES group, the level of significance was set to $\alpha=.05$. ANOVA was used to analyze the differences between the three groups.

\section{RESULTS}

\section{Changes in the number of Caspase -3 reactive cells in the cerebellum}

The number of Caspase -3 reactive cells in the cerebella of ischemia-induced rats at 12 hours postischemia was $2.67 \pm .58$ in the control group, $8.00 \pm$

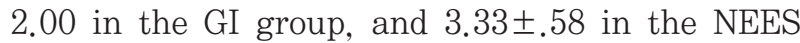
group, showing a significant decrease $(\mathrm{p}<.05)$ in the GI group(Figures 1). The number of Caspase -3 reac $^{-}$ tive cells at 24 hours post-ischemia was $2.33 \pm .58$ in the control group, $14.00 \pm 1.00$ in the GI group, and $11.33 \pm 1.15$ in the NEES group, showing a significant decrease $(p<.05)$ in the GI group. The number of
Caspase -3 reactive cells at 48 hours post-ischemia was $9.67 \pm 2.52$ in the GI group and $8.67 \pm 1.15$ in the NEES group, showing an insignificant decrease compared to the GI group.

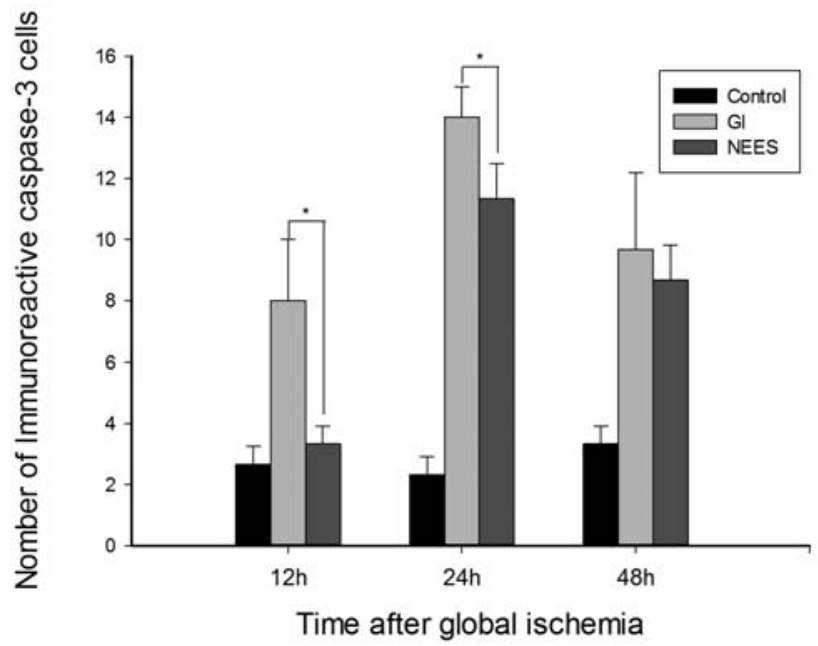

Fig. 1. Effect of needle electrode electrical stimulation on caspase-3 immunoreactive cells in rat cerebellum after transient global ischemia. Control=no surgical procedure; Gl=transient global ischemia; NEES=needle electrode electrical stimulation at 12, 24, and 48 hours after transient global ischemia. Values are the mean \pm SD. Bars with different alphabetic letters in the same times are significantly different(* p<.05).

\section{Changes in the occurrence of the Caspase- 3 pro- tein in the cerebellum}

Occurrence of Caspase-3 in the cerebella of ischemia-induced rats at 12 hours post-ischemia was $165.34 \pm 3.58$ in the control group, $193.76 \pm 2.00$ in the GI group, and $169.59 \pm 4.58$ in the NEES group, showing a significant decrease $(p<.05) \mathrm{com}^{-}$ pared to the GI group(Figure 2). Occurrence of Caspase -3 at 24 hours post-ischemia was $161.78 \pm$ 5.32 in the control group, 202.63 \pm 3.00 in the GI group, and $187.21 \pm 3.15$ in the NEES group, showing a significant decrease $(p<.05)$ compared to the GI group. Occurrence of Caspase- 3 at 48 hours postischemia in the GI group was $179.99 \pm 2.52$, showing a decrease compared to results at 24 hours; however, occurrence in the NEES group was 170.42 \pm 3.15 and showed no significant change. 


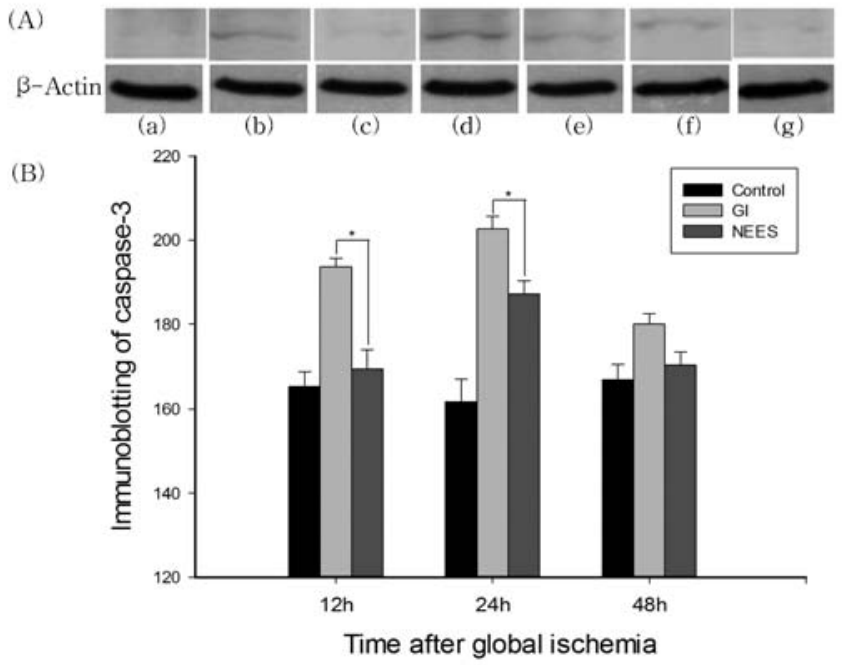

Fig. 2. Effect of needle electrode electrical stimulation on caspase-3 expression in rat cerebellum after transient global ischemia.

(A) Total casapse-3 protein was extracted from cerebellum.

(a) Control group,

(b) $12 \mathrm{~h}$ after transient global ischemia,

(c) $24 \mathrm{~h}$ after transient global ischemia,

(d) $48 \mathrm{~h}$ after transient global ischemia,

(e) needle electrode electrical stimulation at $12 \mathrm{~h}$ after transient global ischemia,

(f) needle electrode electrical stimulation at $24 \mathrm{~h}$ after transient global ischemia,

(g) needle electrode electrical stimulation at $48 \mathrm{~h}$ after transient global ischemia.

(B) Results are expressed as density. Control=no surgical procedure; Gl=transient global ischemia; NEES=needle electrode electrical stimulation at 12, 24, and 48 hours after transient global ischemia. Values are the mean \pm SD. Bars with different alphabetic letters in the same times are significantly different $\left.{ }^{*} p<.05\right)$.

\section{DISCUSSION}

One of the greatest effects of acupuncture therapy is that it can promote speedy recovery from complications related to stroke(9). There are also studies showing that manipulation of certain acupuncture points below the knee may have an effect on blood pressure adjustments(10).

Hyperoccurrence of intercellular Caspase-3 will result in apoptosis(11), and there have been reports that using Caspase-3 activation inhibitors also inhibit apoptosis $(12,13)$. It has also been reported that the amount of Caspase-9, which becomes ele- vated in mice with ischemia-induced brain damage, decreases with NEES(14).

An increase in Caspase-3 levels in all areas of the cerebellum following induction of GI was also observed in the present study. Previous studies have reported positive results from NEES therapy at the 12 hour mark post-ischemia, in relation to the effects of NEES on Caspase-3 immunoreactive cells in the ischemic state(15). These results concur with other studies showing that excessive occurrence of Caspase -3 increases cell death, and that ischemia induces an increase in Caspase-9, which, in turn, activates Caspase- 3 and results in apoptosis. In regards to the effects of NEES, the number of Caspase -3 reactive cells in the cerebellum 12 hours post-ischemia was $8.00 \pm 2.00$ in the GI group and $3.33 \pm 0.58$ in the NEES group, showing a significant decrease compared to the GI group(p<.05). At 24 hours post-ischemia, the number was $14.00 \pm 1.00$ in the GI group and $11.22 \pm 1.15$ in the NEES group, showing a significant decrease as well(p<.05). Occurrence of Caspase- 3 at the 12 hour mark was $193.76 \pm 2.00$ in the GI group and 169.59 \pm 4.58 in the NEES group, showing a significant decrease compared to the GI group(p<.05). Occurrence of Caspase3 at the 24 hour mark was $202.63 \pm 3.00$ in the GI group and 187.21 \pm 3.15 in the NEES group, showing a significant decrease compared to the GI group(p<.05). Based on these results, NEES seems to have a significant effect on Caspase-3 in the cerebellum in an ischemic state at 12 and 24 hours post ischemia. It was concluded that NEES delays the initial occurrence of Caspase-3, resulting in a delay and inhibition of cell death, as well as promotes a decrease in Caspase-3 in early treatment.

In conclusion, NEES delays the occurrence of early stage apoptosis-inducing Caspase-3, delaying and inhibiting apoptosis. Further systematic studies will have to be conducted in relation to the application of this study $\mathrm{s}$ results on stroke patients.

\section{CONCLUSION}

The number of caspase -3 reactive cells in the corpus cerebellum 12 and 24 hours post-ischemia was significantly(p<.05) smaller in the NEES group compared to the GI group. caspase- 3 expression 12 and 24 hours post-ischemia was significantly(p<.05) smaller in the NEES group compared to the GI group. 
Based on these results, NEES seems to have a significant effect on Caspase-3 in the cerebellum in an ischemic state at 12 and 24 hours post ischemia, NEES delays the occurrence of early stage apoptosis inducing Caspase-3, delaying and inhibiting apoptosis. Further systematic studies will have to be conducted in relation to the application of this study's results on stroke patients.

\section{REFERENCES}

1. Sharp FR, Lu A, Tang Y, Millhorn DE. Multiple molecular penumbras after cerebral ischemia. $\mathrm{J}$ Cereb Blood Flow Metab 2000; 20: 1011-32.

2. Runnerstam M, Bao F, Huang Y, Shi J, Gutierrez E, Hamberger A, Hansson H, Viano D, Haglid K. A model for diffuse brain injury by rotational acceleration, IL Effect on extracellular glutamate Intracranial pressure and neuronal apoptosis. J Neurotrauma. 2001; 18(3): 259-273.

3. Hausmann R, Biermann T, Wiest I, Tubel J, Betz P. Neuronal apoptosis following human brain injury. Int J Legal Med 2004; 118(1): 32-36.

4. Fisher M. The ischemic penumbra: identification evolution and treatment concepts. Cerebrovasc Dis 2004; 17(suppl 1): 1-6.

5. Kato H, Konure K. Biochemical and molecular characteristics of the brain with developing cerebral infarction. Cellular and Molecular Neurobiology 1999; 19: 93-108.

6. Kochanek PM, Hallenbeck JM, Polymorphonuclear leukocytes and monocytes/macrophages in the pathogenesis of cerebral ischemia and stroke. Stroke, 1992; 23:1367-79.

7. Zheng Z, Zhao H, Steinberg GK, Yenari MA. Cellular and molecular events underlying ischemia-induced neuronal apoptosis. Drug News Perspect 2003; 16: 497-503.

8. Rao RV, Peel A, Logvinova A, Rio GD, Hermelm E, Yokota T, Goldsmith PC, Ellerby LM, Ellerby HM, Rredesen DE. Coupling endoplasmic reticulum syress to the cell death program: role of the ER chaperone GRP78. FEBS letters 2002; 514: 122-128.
9. Inoue I, Chen L, Zhou L, Zeng X. Wang H. Reproduction of scalp acupuncture therapy on strokes in the model rats, spontaneous hypertensive rats-stroke prone (SHR-SP). Neurosci Lett 2002; 333(3): 191-194.

10. Kim KH, Lee YH. The Effects of Acupuncture on heart rate and blood pressure in rats. The $J$ of Korean Acupuncture \& Moxibustion Society 1986; 3(1): 39-52.

11. Muzio M, Chinnaiyan AM, Kischkel FC, O'Rourke K, Shevchenko A, Ni J, Scaffidi C, Bretz JD, Zhang M, Gentz R, Mann M, Krammer PH, Peter ME, Dixit VM. FLICE, a novel FADD-homologus ICE/CED-3-like protease, is recruited to the CD95(Fas/APO-1) death-inducing signaling complex. Cell 1996; 85: 817-827.

12. Srinivasula SM, Manzoor A, Teresa FA, Gerald L, Emad SA. Molecular ordering of the Fas-apoptotic pathway: the Fas/APO-1 protease Mch5 is a CrmA-inhibitable protease that activates multiple Ced-3/ICE-like cysteine protease. Proc Natl Acad Sci USA 1996; 93(25): 14486-14491.

13. Zhou Q, Snipas S, Orth K, Muzio M, Dixit VM, Salvesen GS. Target protease specificity of the viral serpin CrmA, Analysis of five caspases. J biol Chem 1997; 272(12): 7797-7800.

14. Wang SJ, Omori N, Li F, Jin G, Zhang WR, Hamakawa Y, Sato K, Nagano I, Shoji M, Abe K. Potentiation of Akt and suppression of caspase-9 activations by electroacupuncture after transient middle cerebral artery occlusion in rats. Neurosci Lett 2002; 331(2): 115-118.

15. Kim SW, Lee JS, Park SG, Kang HJ, Kim YS, Yoon YD, Yang HS, Lee HG, Kim SH. The effects of needle electrode electrical stimulation on cellular necrosis blocking the forebrain after induction of ischemia. J int Acad Phys Ther Res 2010; 1: $10-18$ 